\title{
TECHNICAL PROBLEMS IN FOOD AND DRUG LAW ENFORCEMENT
}

\author{
C. W. Crawpord*
}

The profound changes in our economic system brought about in the past quarter century by technological developments in the industrial world have been attended by a striking evolution of the methods of manufacture and distribution of foods and drugs. Shifting sources of raw materials, introduction of new products and processes, increasing plant capacity for mass production, sharpening competition, consumer demand for more ready-to-serve foods, all have contributed to the swiftly changing picture. However real may be the social benefits of transferring the preparation of the bulk of our foods from the kitchen to the factory, the advantages have not been always unalloyed. While certain hazards like botulinus poisoning in canned foods have been practically eliminated by the carefully controlled time and temperature of cooking generally prevalent in commercial canneries, other hazards both to the health and pocketbook of the consumer arise from new technical methods and cutthroat competition. New substances of dubious physiological effect may find their way into foods, or well known poisons may be introduced by new processes. Guided by expert technical advice, sharp-shooting manufacturers resort to sophistications. New drugs, or old drugs in new combinations, may fall short of their reputed potency. It is in these fields that the regulatory technician finds his problems.

Lacking adequate funds for prompt correction of all illegal abuses as they arise in the vast field of food and drug production and distribution, regulatory organizations must adopt a system of projects under which the appropriation allotted to each commodity group is proportional to the importance of the violations occurring in the group as measured by their seriousness to consumers. This plan insures greatest attention to offenses against health. In proceeding against them some of the gravest technical difficulties are met.

It has been rightly said that the policy of the Federal Food and Drugs Act regarding added poisonous substances in food is an inverted one since the law places the obligation on the Government to show that the contaminated food may be harmful to health, rather than on the manufacturer to show that it will not. There is a wide range beween dosages of poisons which produce immediate and definitely identifiable

- B.S., I909, M.S., I916, Oklahoma Agricultural and Mechanical College. Chief, Office of Interstate Supervision, Division of Food and Drug Administration, United States Department of Agriculture. 
harmful effects and the quantities which may, on prolonged use, cause a gradual undermining of health. While the Supreme Court has held that if a food, by reason of an added poisonous ingredient, may possibly injure the health of the strong or the weak, the old or the young, the well or the sick, it comes within the ban of the statute, ${ }^{1}$ the toxicologist testifying in a court trial must nevertheless base his conclusions on tangible facts rather than on mere forebodings of harm. Where poisons in foods are found in minute quantities the proof of their harmfulness may present most serious difficulty. Complications arise from the fact that traces of poison continuously consumed may manifest results only after a period of years; first evidence of poisoning from infinitesimally small daily doses of lead have appeared as long as a decade or more after the beginning of the exposure. If the particular poison is a new chemical about which little is known, medical and pharmacological literature may afford no help. If it has been extensively investigated observations may have been confined to larger doses than occur in the food under consideration. Recourse must be had in many cases to protracted and expensive laboratory work on test animals, and here the picture is again clouded by the uncertainty of translating effects on animals into effects on man.

If the poison is one recently introduced in foods, methods for its quantitative determination may be lacking. Intensive research is then necessary to devise reliable methods from the results of which the toxicologist can draw his conclusions. These methods must be not only accurate, but must have the virtue of speed so that many samples can be examined and prompt results obtained by a limited laboratory personnel.

Certain fluorine compounds were introduced a few years ago as insecticides for fruits and vegetables. Pharmacological literature contained much evidence that some of these compounds are acutely poisonous in fairly large doses. But there was little information on the particular compounds used in the new insecticides, and none at all on the minute quantities that would be consumed as spray residue. Available chemical methods proved inadequate for determining such quantities. One break of luck came for the regulatory technicians when at about this time workers in the University of Arizona announced proof that mottling of human teeth, prevalent in certain areas of the state, was caused by traces of fluorine naturally present in the water supplies. Fluorine interfered with the deposition of lime in the teeth. Structural weakness as well as discoloration followed. These facts suggested other questions. How much fluorine would cause the damage? If it acted in this way on the teeth, might it not interfere also with the deposition of lime in the bones? Might it affect other parts of the body? By using various fluorine compounds in the diets of laboratory animals the Arizona workers and other scientists set out to find the answers. Regulatory chemists joined in the hunt for suitable quantitative methods. These have now been perfected and the pharmacological work has sufficiently

${ }^{1}$ United States v. Lexington Mill \& Elevator Co., 232 U. S. 399 (I9r4). 
progressed to permit tentative conclusions as to the quantity of fluorine which may be injurious. Undoubtedly it will be many years before the information on fluorine approaches in comprehensiveness that now available on such historic poisons as arsenic and lead.

While the most important function of the regulatory technician is to acquire facts on which the provisions of the law can be invoked for the protection of public health, he has also countless intriguing problems in the detection of violations which merely deplete the consumer's purchasing power, and incidentally enhance that of the manufacturer. Peculiarly enough, some of the strongest court interpretations of the law have arisen out of cases where the damage to the consumer was comparatively small and the food involved of minor importance. Such was the so-called "Vinegar Case," in which the United States Supreme Court held that the law forbids deception conveyed by indirection and ambiguity as well as by direct misstatement of fact. ${ }^{2}$ Back of this litigation lay the solution of a technical problem typical of the simpler, garden variety. The case was based on a product labeled "Apple Cider Vinegar" made by soaking dried apples in water, expressing and fermenting the infusion. The cost of producing this vinegar was less than that of vinegar made from the juice of fresh apples. Laboratory methods had not been developed for detecting the substitution of the cheaper article; in fact, the conventional analytical procedure for vinegars failed to show any difference in the two products. The law does not authorize factory inspection, and it was unlikely that the manufacturer would permit inspectors to witness the manufacture of the vinegar and its subsequent delivery in interstate commerce. It was necessary, therefore, if effective regulatory action was to be taken, to develop methods whereby the two vinegars could be differentiated through objective examination of samples collected from interstate shipments. It was known that the dried apples used by the manufacturer had been bleached by the usual process of exposing them, while drying, to the fumes of burning sulphur; otherwise the finished vinegar would have been too dark in color. It seemed probable that the sulphur fumes absorbed in the dried apples would be carried into the finished vinegar as sulphates. A short investigation showed this was just what happened. While cider vinegar contains some sulphates, the dried apple product contains several times the normal quantity. Seizures were made on this evidence, but the manufacturer let them go by default while his chemist sought ways and means of eliminating the incriminating sulphur. An answer was quickly found in the addition of carefully calculated amounts of barium carbonate which combined with the excess sulphates to form one of the least soluble compounds known, barium sulphate. When this settled out, the vinegar had a normal sulphate content, and the regulatory chemist had to begin all over again. Some time was spent in investigating the volatile constituents of vinegar on the theory that in drying apples some change would occur in these which could be detected in the vinegar. But as so often happens in scientific research, results were negative or at least too uncertain for court use.

${ }^{2}$ United States v. 95 Barrels of Vinegar, 265 U. S. 438 (1924). 
The attack shifted to an attempt to detect the infinitesimal quantity of barium sulphate that might still be in the vinegar, since no substance is known to be wholly insoluble. By concentrating a large quantity of the vinegar to about I/200 part of its original volume, employing complex chemical means to get rid of the interfering substances normally present in vinegar, a minute quantity of a white precipitate could be filtered off. Was it barium sulphate? The spectroscope answered in the affirmative. No barium could be found in cider vinegar. This evidence, backed by the fact that the factory was receiving amounts of barium carbonate for which it could have no other use, was the ground for further seizures. Thus cornered, the manufacturer in defense of his lucrative business turned to court battle with the final result that the Supreme Court sustained the charges in its sweeping interpretation of the misbranding provisions of the Act.

Technological developments in mass production, desirable in themselves, sometimes present opportunities for abuse by unscrupulous manufacturers. The old fashioned housewife who put up her own jellies was usually worried about her results until the hot mixture of fruit juice and sugar actually jelled in the glasses. Only the most skillful manufacturers who knew how to buy fruits in just the proper stage of maturity undertook to put out a varied line of jellies other than the cheap apple-base type. Then commercial pectin was developed. This is the fruit substance which, with sugar and the acidity usually normal to fruit juice, causes jelly to jell. It is abundant in apples and in the rinds of citrus fruits. It can be produced cheaply from such by-products as apple pomace and citrus fruit peel. The pectin content of fruits decreases with maturity so that many fruits at the most luscious stage of ripeness will not make jelly without long flavor-destroying boiling, if at all. By adding a few tenths of a per cent of pectin they jell with a short cook. But a "jell" can be made from water, sugar, acid and pectin with no fruit juice whatever. Such a product has neither the appearance nor taste of jelly, but the manufacturer who wants to cut down on the expensive fruit juice ingredient can use half fruit juice and half water. The flavor and color are attenuated, but the product is not readily differentiated from the straight fruit juice article. A manufacturer so inclined can take advantage of the same property of pectin by substituting water for part of his fruit in jam and preserves. If he uses no pectin the fruit would be likely to separate to the top of the jar and thus advertise its deficiency, but with pectin to "set" the mass the fruit remains uniformly distributed and the deficiency is concealed.

When pectin became commercially available many manufacturers did not use it solely to improve their output. Methods to detect even gross deficiencies in the fruit content of jams and jellies had not been worked out. The technical difficulties were emphasized by the wide variation in the composition of fruit. The ancient saw, "Nature abhors a vacuum," has given way to the more truthful observation, "Nature abhors precision." In putting together the constituent parts of fruits she is acting the part. Composition varies with horticultural varieties, geographic location, weather 
conditions, degree of maturity, and other factors. "Big Joe" strawberries grown in the Norfolk area during a rainy season differ from fruit of the same plants in a dry season and are likely to differ even more from the "Perfection" variety grown in the same place or in Tennessee or Oregon. This is also true of other preserving fruits. Hundreds of analyses failed to disclose the occurrence of any single constituent in sufficiently constant proportion to serve as an accurate index to the quantity of fruit in the finished jam or jelly. But a study of the mass of analytical data began to show that some of the ratios between two or more constituents are fairly constant. By working out several of these for each fruit, the chemist was able to determine with acceptable accuracy the fruit content of finished jams and jellies. Before this time-consuming work could be completed the preserving industry had been demoralized by the abuse of pectin, with the consumer acting the usual rôle of the innocent bystander. It took years of extensive regulatory proceedings by the Government, aided by the better element of the industry, to correct the situation.

Progress in scientific knowledge sometimes reveals unsuspected and unintentional abuses of public welfare, none the less damaging because unintentional. It may be that we are now faced with this situation in the growing practice of adding vitamin D to various infant foods. This vitamin in proper dosage is almost specific for the prevention and cure of infantile rickets, a disease all too common in northern latitudes where, because of their limited exposure to sunshine, babies may not obtain an adequate supply of their own vitamin $D$ to supplement that contained in their diet. Cod liver oil and several other fish oils are rich sources of this vitamin, but it is also extensively produced artificially, notably by irradiating a substance called ergosterol with ultraviolet light. The potency of the manufactured product is determined by feeding it in measured quantities to a group of rats in which rickets has been artificially produced, and comparing its effects with those obtained by feeding a similar group with measured quantities of cod liver oil. Knowing the dosage of cod liver oil required for an infant, the manufacturer using irradiated ergosterol in his baby food has been adding an equivalent quantity of the rat-standardized product. In his labeling and advertising claims asserting the food is equal in vitamin $\mathrm{D}$ to a stated amount of cod liver oil, he has had the backing of vitamin experts generally; but recognized authorities have now reported results on feeding a vegetable oil solution of irradiated ergosterol, it is only about two-fifths to one-third as potent when fed to babies as when fed to rats. Will this discrepancy be found in baby foods containing irradiated ergosterol? Have we over-estimated the power of such foods to prevent or cure rickets in children? No one can say with certainty. The answer must be found by delving deeper in the field of nutrition than science has so far gone.

The regulatory technician has sometimes solved baffling problems only to suffer the disappointment of failure to get his facts across to juries of laymen in the trial of cases. Years ago the sanitary conditions in many tomato catsup plants were atrocious. Field-run tomatoes were put through without bothering to sort out rotten 
fruit; utensils, tanks and pipe lines were unwashed and accumulated coatings of slimy, foul smelling material. Spices masked the undesirable flavors that might otherwise have been manifested in the finished product. No method was known whereby such filthy material could be detected by objective examination. It was known that spoilage is caused principally by two classes of microörganisms, molds, and yeast, but these may be on sound tomatoes and their mere presence in catsup is not proof of spoilage. Microscopists devised a method for counting the mold filaments and yeast cells in the catsup and found by making hundreds of tests that there is a definite relationship between these counts and the percentage of rotten material in the raw tomatoes or the degree of spoilage due to contamination and fermentation in the factory. Seizures were made of shipments of catsup which the microscope showed to have been prepared from thoroughly rotten stock. In the trial of one of the initial cases the defense counsel brought out the intricate technical details of the method and skilfully effected the confusion of the jury. Much was made of the point that from each of the several bottles in the sample only one or two drops of the catsup were actually examined. Should a whole carload of this splendid food product be destroyed on what an impractical scientist thought he saw in a few drops through a high powered microscope? Traditional American freedom must be preserved against the encroachments of mendaciously meddling bureaucracy. The jury found for the claimant, and the catsup was released, perhaps to be consumed on the tables of some of those who rendered the verdict. But this decision did not impair the inherent value of the method. It was soon recognized and adopted generally by food technicians. A similar attack on the method today would probably fail because of the supporting testimony that would be available from technicians in the industry itself. And through the years since the method was devised it has brought revolutionary improvements in the sanitary conditions of catsup factories.

Perhaps the most difficult scientific testimony to present to a lay jury is that required for the successful prosecution of fake medicines. Many laymen believe in the curative effects of drugs with far greater conviction than they hold for their views in other fields of science. They had influenza; the doctor administered aspirin; they recovered. Aspirin is therefore a remedy for influenza. They have no notion of the prevailing medical opinion that the sole function of aspirin is to lessen somewhat the malaise of the patient; that it exerts no effect on the progress of the infection which causes the disease. There is a will to believe in the therapeutic efficacy of drugs that baffles understanding until we are reminded that recovery from disease is spontaneous in about four-fifths of the cases and occurs irrespective of the use of medicaments. This passion for belief in miracles from pill boxes was recognized by Judge Geiger in the following words from his charge to the jury in a case against a nostrum bearing flamboyant therapeutic claims:

Now, in that connection you should examine this language in the light of the purpose of this law, which is to protect humankind against the consequences of human weakness, or human frailty, of human credulity or the disposition to believe, or of human gullibility. 
You should examine it in the light of the disposition of the ordinary humankind to wish to believe in the potency of remedial agents to relieve them from ills from which they are actually or conceivably suffering. ${ }^{3}$

This attitude by lay jurors toward the healing power of drugs handicaps the effective presentation of medical testimony and contributes materially to the difficulty already inherent in patent medicine cases, that of proving fraud. Involving as it does the establishment of what the nostrum maker actually thinks of his product as compared with what he says about it, this difficulty is sometimes a staggering one. Technically trained inspectors ferret out the required evidence of bad faith. Perhaps local physicians have told the manufacturer his medicine is worthless. Dissatisfied customers may have reported to him their sad experiences. He may have continued the publication of testimonials after he knew the writers were dead from the disease supposed to have been cured. He himself may have had the disease and, not relying on his own concoction, sought the attention of physicians. In countless ways his duplicity is revealed. Unearthing these facts requires ingenuity and persistence of as high order as the solution of a knotty laboratory problem.

The analyst's job of unscrambling some patent medicines, so the physician can evaluate their therapeutic worth makes the most intricate jig-saw puzzle look simple. The manufacturer who offers to treat your self-diagnosed distemper has literally thousands of materials he can choose from to make an infinite number of combinations exasperatingly difficult to unravel. Included in these may be such weird Chinese medicaments as powdered bedbugs and deer-horn, or Voodoo decoctions of nondescript herbs, as well as conventional drugs like quinine or. Epsom salts. Some of the herb medicines may be composed of extractives from a number of plants, none of which contains characterizing constituents for which identification tests are known. The successful merchandizing of many preparations depends upon the fabrication of a background of some great scientific discovery unknown as yet to chemists and doctors. Experience has shown that in prosecuting such cases the defense is apt to center on a claim for some mysteriously potent substance the analyst has been unable to find; that this substance was the discovery of the late Dr. Hokum, renowned specialist, who, inspired by his pity for stricken humanity, labored a lifetime to develop this matchless boon to health and happiness. Only by the most thorough and painstaking investigations can analysts and inspectors prepare themselves to meet this counter-attack.

The formulation of food standards to aid in the control of so-called economic adulterations often requires laborious amassing of technical data. The recently announced standard for moisture in dried apricots will serve to illustrate. This commodity is made by evaporating moisture from ripe apricots, but it is neither desirable nor practicable to remove all the moisture. At what point in moisture content does. the article become a dried apricot? Too much moisture is conducive to spoilage but what is more important is that the consumer is required to pay for it at dried

'Reported in Notice of Judgment 5906, U. S. Dept. AGr. S. R. A,. Chem. Supp. 49, at 510. 
fruit prices. If the product contains too little moisture it is hard, unattractive, and undesirable. Investigation showed a general agreement among consumers that they expect the fruit to contain enough moisture to give it pliability and other desirable characteristics but no more. Just what that meant in terms of percentage of moisture was a question which could be answered only by determining moisture content and physical condition of hundreds of samples, keeping in mind always the possible influence of varietal, geographical, and seasonal factors. The standard for moisture thus set does not in itself have the effect of law since the food and drugs act does not authorize administrative establishment of legally binding standards except in the limited field of canned foods. But the data obtained by the investigation will be useful in sustaining cases in which it will be alleged, not that the fruit differs from the standard, but that it contains excessive moisture and is not entitled to be sold as dried apricots.

The regulatory technician in the food and drug field is unlikely to find himself without the challenge of problems sufficiently interesting and inspiring to bring forth the best he can give. He may be favored by neither fame nor substantial remuneration but he has whatever satisfaction may be derived from the knowledge that solution of his problems is a tangible contribution to social welfare. 